\title{
A Novel IoT based Solution for Monitoring and Alerting Bronchial Asthma Patients
}

\author{
Sreeja Gundu* \\ B.Tech. Student, Department of Electronics and Communication Engineering, JNTUH College of Engineering, \\ Sultanpur, India \\ *Corresponding author: gundu.sreeja@gmail.com
}

\begin{abstract}
Bronchial Asthma or simply Asthma is a prime concern for people of all the ages. There are many people around the world suffering from asthma. Asthma in a chronic condition where in the patient's airways inflames and swells with thick mucus. This condition can make difficulty in breathing and trigger with cough and with a whistling sound when patient breathe out. Mainly asthma is a disease where patient feels difficult to breath and sometimes this becomes chronic where nebulization becomes compulsory. Symptoms for asthma are whistling, cough and difficulty in breathing etc. Hence there is an immediate need for some device which not only suggests how many puffs of inhaler has to be taken and at the same time need to warn the patient about severity regarding the surrounding atmosphere with respect to causes of severe illness. There are many IoT based electronic devices developed to detect asthma triggers. The proposed electronic device detects the trigger as well as notifies the patient with an alert to inhale the required amount of dosage. Proposed model continuously senses the atmosphere for different parameters that may cause difficulty in breathing and immediately alerts the patient to move from that place to safe place, thereby saving patient's life and reducing risk.
\end{abstract}

Keywords: Asthma, IoT, Puffs, Triggers.

\section{Introduction}

Asthma has been the most common health problem with people of all the ages almost in every country. It is affected due to genetic or environmental factors like air pollution and allergens. Cold air, tobacco smoke, exercise, stress and bacterial [1], [2] or viral infection are few triggers. It affects nearly 339 million persons across the globe. Though it has no cure, we can avert by avoiding triggers and proper medication. Patients with asthma disease feel difficulty in breathing [3], [4], [5] when they are outside home and pollution is more, during winter and rainy seasons where temperatures drop drastically.

From the analysis regarding asthma disease, it is evident that the main parameters effecting health of patients are Humidity, temperature, Dust [6], [7]. Our proposed method uses pulse or heartbeat to track the condition of the patient while sensing the surrounding atmosphere to trigger asthma symptoms. There are precise threshold values above which if these triggers reached cause a severe threat and need immediate medical attention. There are several IoT based products in the market which detects these triggers. The proposed model detects the triggers and sends an alarming notification to mobile phone recommending inhaling the required number of puffs and directs to a safe place.

\section{Materials and Methods}

Input:

DHT22 (Temperature and humidity sensor),

MAX30100 (oximeter and pulse sensor),

GP2Y1010AU0F (optical dust sensor).

Process: ESP8266 (Nodemcu)

Output: Blynk

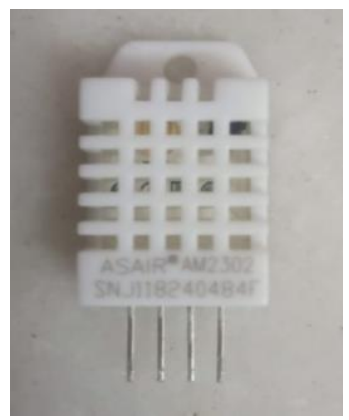

Fig. 1. DHT22

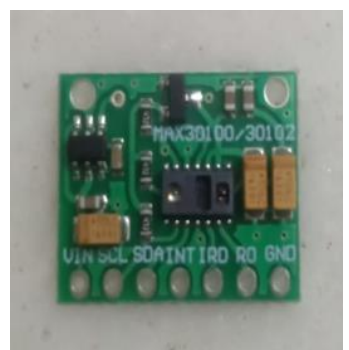

Fig. 2. MAX30100

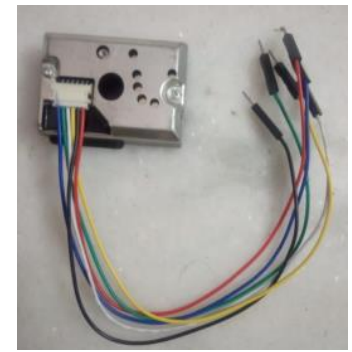

Fig. 3. GP2Y1010AU0F 


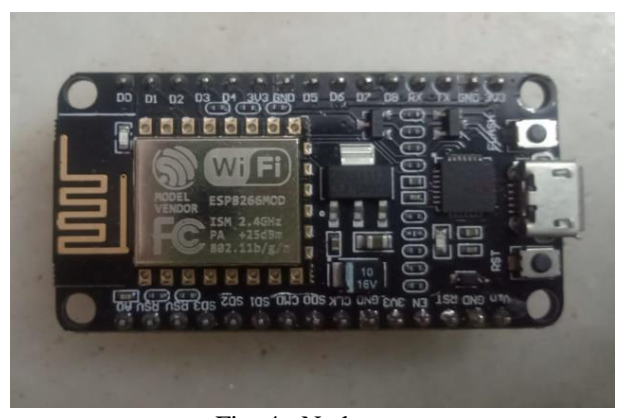

Fig. 4. Nodemcu

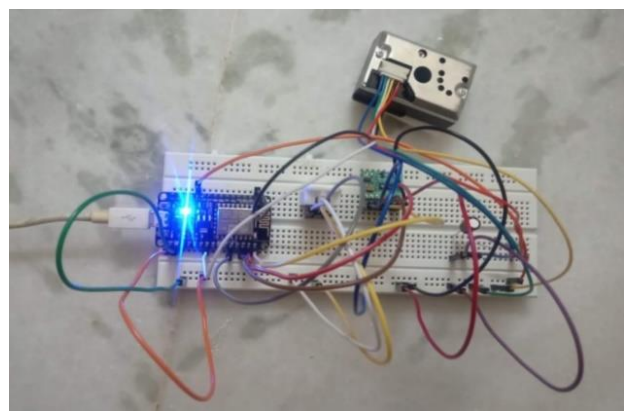

Fig. 5. Real time operation

\section{Description:}

Fig. 1, $2 \& 3$ are the sensors that read the input data. Fig. 4 is the Wi-Fi module microcontroller that processes the data and sends output to blynk app. Fig. 5 is the working model in real time application.

\section{Existing Model}

The present models are IoT based electronic devices that detect asthma triggers from the surroundings, records the data and displays the readings on to the mobile phone [8]. According to these readings, the patient inhales the prescribed number of puffs [9]. As triggering is important for asthma patient regarding number of puffs to be inhaled from inhaler same time it is also important to suggest how risky is to stay in a place where parameters that triggers asthma symptoms cross predefine threshold values that causes risk to patient.

\section{Proposed Method}

The proposed model records the readings from sensors. If the values go beyond the threshold values, an alarming notification directs to mobile phone via blynk app warning person to inhale the required number of puffs and move away from the place to a safe place.

The threshold values of triggers are:

Humidity $-50 \%$

Temperature - less than $21^{\circ} \mathrm{C}$ and greater than $45^{\circ} \mathrm{C}$

Pulse - 110 BPM

Dust $-600 \mathrm{ug} / \mathrm{m}^{3}$

The dose to inhale depends on the number of triggers crossing the threshold values. If any of the above triggers goes beyond the threshold value, then an alert "High risk! Please inhale a puff and move away from this place" is sent to blynk app. If more than a trigger crosses the threshold value, then alert "High Risk! Please move away from this place, inhale a puff, and seek medical attention" directs the blynk app until the person lands to a safe place. This way a person can prevent an asthma attack. After a person reaches a safe place, blynk notifies "You are safe now!"

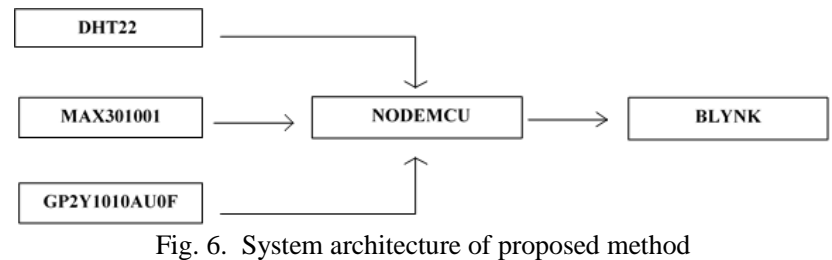

\section{A. $D H T 22$}

DHT22 sensor reads the temperature and humidity values from the surroundings when $5 \mathrm{~V}$ has connected from nodemcu. When the temperature readings do not lie in the range $21^{\circ} \mathrm{C}$ to $45^{\circ} \mathrm{C}$ or humidity readings go beyond 50 , an alert to inhale a puff and move from the place will direct to blynk cautioning about triggers to prevent an attack.

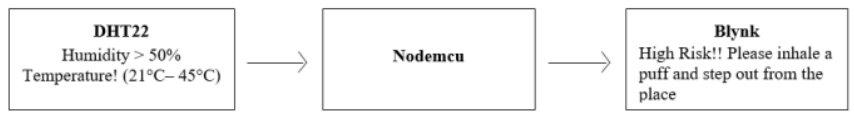

Fig. 7. Working of DHT22

\section{B. MAX30100}

MAX30100 is an oximeter and heart rate sensor. This sensor reads the pulse level when nodemcu supplies the power. A pulse rate of 110 and above is a life threat for the asthma patient and requires emergency medical care. If the pulse level goes beyond 110, an alert to inhale puff and seek medical attention will direct to blynk.

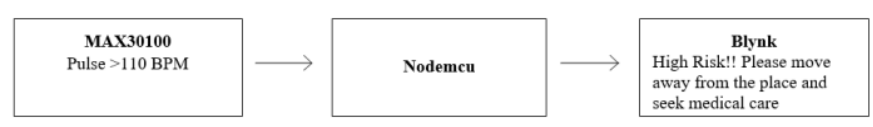

Fig. 8. Working of MAX30100

\section{GP2Y1010AUOF}

GP2Y1010AU0F is an optical dust sensor that detects cigarette smoke, dust mites, mold, etc. Dust accompanied by humidity or temperature turns to be a threat for asthma patient.

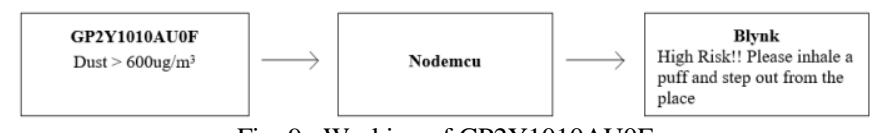

Fig. 9. Working of GP2Y1010AUOF

\section{Results}

The Sensor values of the pulse, oxygen levels, temperature, humidity and dust recorded by the sensor have displayed on the blynk app. The output screen shots in real time are taken and shown below. The total analysis is carried out through one 


\section{IJRESM journals.resaim.com/ijresm | ISSN (Online): 2581-5792 | RESAIM Publishing}

complete day and at different times of the day where different parameters such as temperature, dust and humidity changes. The sensors said above are used effectively and tested in real time at different times and different places in a day. The results obtained are shown in table 1 below and analysis is carried out on this data.

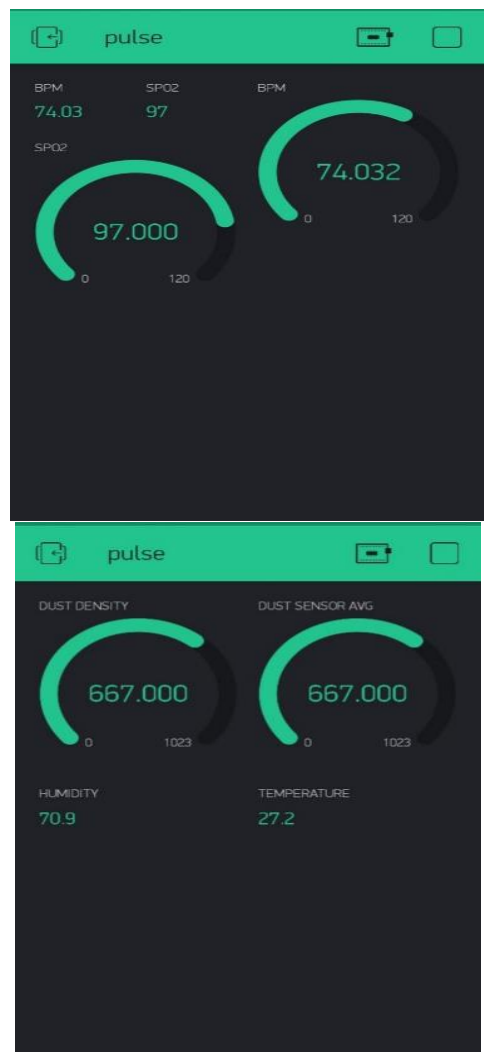

Fig. 10. Pulse, Oxygen, Temperature, Humidity and Dust readings on blynk

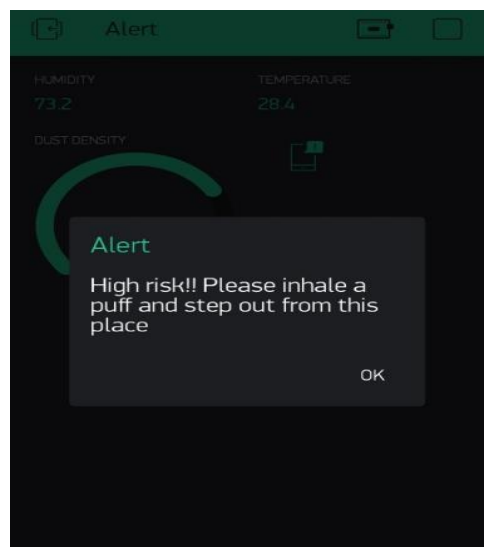

Fig. 11. Blynk notification to alert person

An alert directing to a safe place and the required dose to inhale is displayed on blynk app to prevent an asthma attack. When a person reaches a safe place, a notification stating "you are safe now!" is directed to blynk.

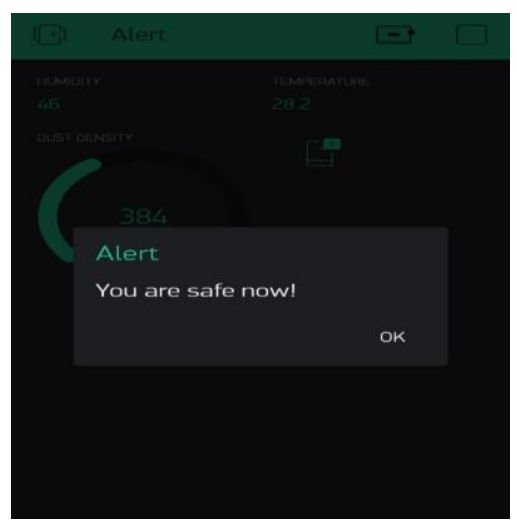

Fig. 12. Blynk notification to indicate safe

Temperature \& Humidity Graphical Analysis:

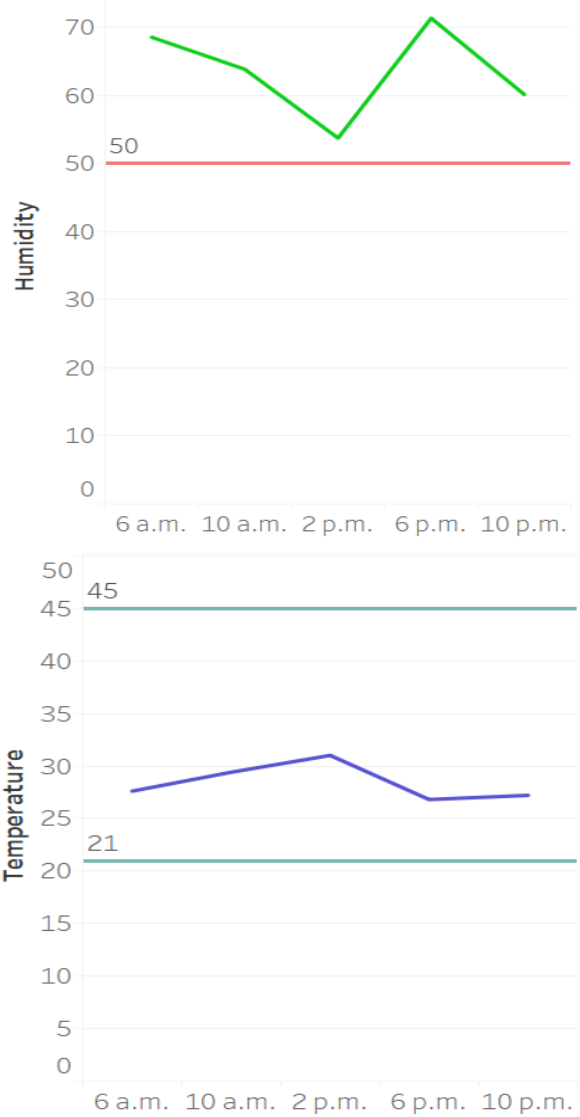

Fig. 13. Graphical analysis of temperature and humidity data

Table 1

Sensors data at different times in a day

\begin{tabular}{|l|l|l|l|l|l|}
\hline Time & Temperature $\left({ }^{\circ} \mathbf{C}\right)$ & Humidity (\%) & Pulse (BPM) & Oxygen & Dust $\left(\mathbf{u g} / \mathbf{m}^{\mathbf{3}}\right)$ \\
\hline 6 a.m. & 27.6 & 68.5 & 73 & 99 & 389 \\
\hline 10 a.m. & 29.4 & 63.8 & 69 & 98 & 539 \\
\hline 2 p.m. & 31 & 53.7 & 71 & 97 & 684 \\
\hline 6 p.m. & 26.8 & 71.3 & 68 & 98 & 621 \\
\hline 10 p.m. & 27.2 & 60.1 & 72 & 98 & 485 \\
\hline
\end{tabular}


The graph depicts the temperature and humidity variations at various intervals of the day. The threshold values are $21^{\circ} \mathrm{C}$ and $45^{\circ} \mathrm{C}$ for the temperature and $50 \%$ for humidity. According to the graph, the best time for the person to go out is in the afternoon. There are high chances of an asthma attack in the early morning and evening. So it is better to stay at home at these intervals.

Pulse and Dust Graphical Analysis:

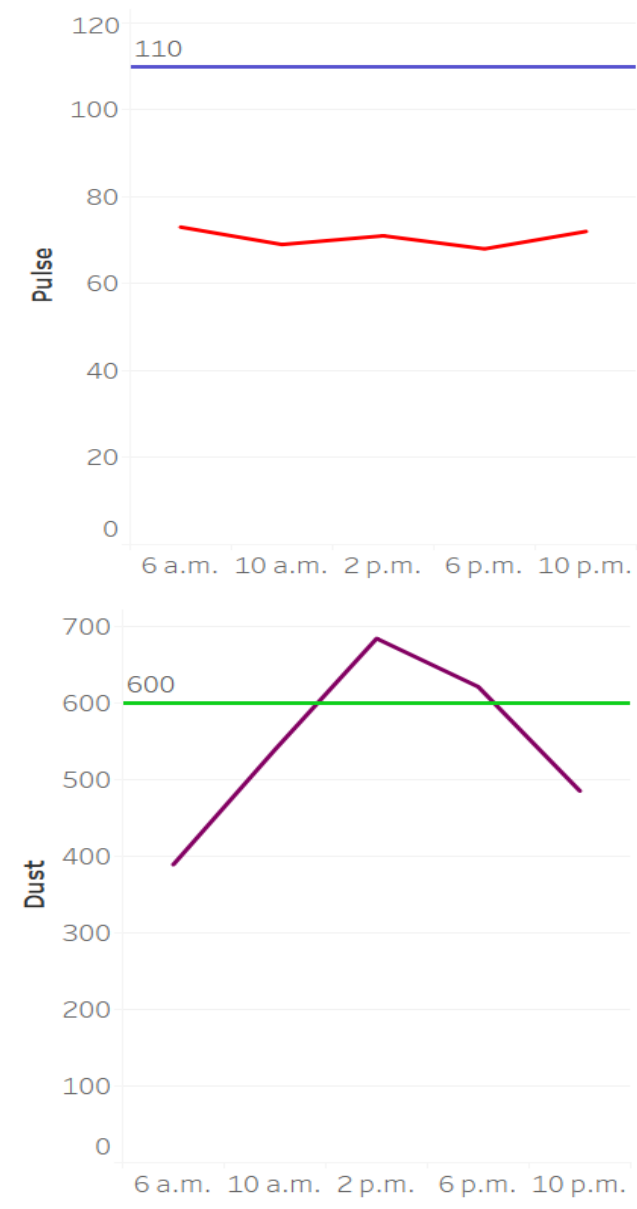

Fig. 14. Graphical analysis of Pulse and Dust readings

The graph depicts variations of pulse and dust at various intervals of the day. The threshold value for the pulse is 110 $\mathrm{BPM}$ and for dust is $600 \mathrm{ug} / \mathrm{m}^{3}$. The pulse level rises during any panic situation, anger, fear or stress. If pulse level rises above 110 BPM, a person needs immediate medical care. Dust levels are high in the afternoon. Dust accompanied by temperature or humidity turns to be a cause for the attack.

By observing the above graphs, it is very much evident and inline to observations that between $2 \mathrm{pm}$ and $6 \mathrm{pm}$ there is a high risk for asthma patients going out which may be because of heavy traffic causing more smoke and moisture in air at $6 \mathrm{pm}$ causing sudden variation in humidity and dust prevails difficulty in breathing.

\section{Conclusion}

The proposed model is a handy IoT based electronic device for asthma patients. The DHT22, GP2Y1010AU0F and MAX30100 sensors read the data and send it to microcontroller Nodemcu. From this proposed work where different parameters which triggers asthma are sensed with sensors and analyze the data received from sensors thereby alerting patient for exact dosage to be inhaled from inhaler. Advantage of proposed method is that if the patient doesn't carry inhaler, existing methods triggers only number of puffs to be inhaled but cannot alert patient about risk involved around in atmospheric changes. Our proposed method not only alerts patient for exact dosage of inhaler as well in the absence of inhaler patient could know changes in atmospheric surroundings and notifies with alert message to move away to safe place. If the sensors data cross the threshold values, an alert is sent to the person via blynk to inhale the required number of puffs and move to a safe place. When a person reaches a safe place, it again directs a notification stating the person is safe. This model prevents the person from having an attack and saves their life by landing them to a safe place.

\section{References}

[1] Ellwood P, Asher MI, Billo NE, Bissell K, Chiang CY, Ellwood EM, ElSony A, García-Marcos L, Mallol J, Marks GB, Pearce NE, Strachan DP. The Global Asthma Network rationale and methods for Phase I global surveillance: prevalence, severity, management and risk factors. EurRespir J. 2017.

[2] Mehmet Taştan, Hayrettin Gokozan (August 2019). Real-Time Monitoring of Indoor Air Quality with Internet of Things-Based E-Nose.

[3] Millqvist, E. B. (1987). Occurrence of breathing problems induced by cold climate in asthmatics--a questionnaire survey. European journal of respiratory diseases, 71(5), 444-449.

[4] Mokhloss I. Khadem, G. S. (2012). Wireless Measurement Node for Dust Sensor Integration. SENSORCOMM 2012: The Sixth International Conference on Sensor Technologies and Applications.

[5] ValentinaPetkova (Jan. 2008). Pharmaceutical care for asthma patients: A community pharmacy-based pilot project. Scholarly Journals.

[6] Man Sing Wong, Tsan Pong Yip, EsmondMok (November 2014). Development of a Personal Integrated Environmental Monitoring System. Sensors, 14, 22065-22081.

[7] Euan R. Tovey, Martin D. Chapman, Clive W. Wells, and Thomas A. E. Platts-Mills (January 05, 1981) The Distribution of Dust Mite Allergen in the Houses of Patients with Asthma. ATS Journals.

[8] Donald W. Cockcroft, Veronica A. Swystun, "Asthma control versus asthma severity," Journal of allergy and clinical immunology, June 1996.

[9] B. V. D. S. Sekhar et al., "A Novel Voice, Sensor and Thought Controlled Robotic Arm," International Journal of Engineering Sciences \& Research Technology, 6(6), June 2017, pp. 531-536. 